\title{
ÉTICA DE LA PARTICIPACIÓN CIUDADANA EN LOS DISCURSOS PERIODÍSTICOS DIGITALES
}

\author{
Jesús Cruz-Álvarez y Juan-Carlos Suárez-Villegas
}
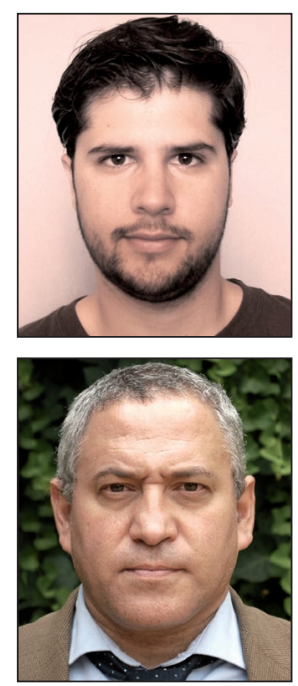

Jesús Cruz-Álvarez es licenciado en periodismo por la Universidad de Sevilla (2006-2011). Actualmente cursa el master "Cultura de paz, conflictos, educación y derechos humanos" de la Universidad de Córdoba. Miembro del grupo de investigación "Estudios en Comunicación, Política y Cambio Social" (SEJ456), e investigador del proyecto de I+D+I "Desafíos éticos en el periodismo digital. Análisis comparativo entre cinco países europeos" (CSO2011-26620).

j.c.alvarez88@hotmail.com

Juan-Carlos Suárez-Villegas, profesor titular de la Univ. de Sevilla (US) en el depto. "Metafísica y Corrientes Actuales de la Filosofía, Ética y Filosofía Política", es director del grupo de investigación "Pensamiento Crítico, Comunicación y Derechos Humanos". Imparte la asignatura "Ética y deontología periodística" en la Facultad de Comunicación de la US. Ha dirigido el Congreso internacional de ética de la comunicación, celebrado en la US en 2011. Es director del proyecto "Desafíos éticos en el periodismo digital. Análisis comparativo entre cinco países europeos".

Universidad de Sevilla Facultad de Comunicación. Despacho f-3 Av. Américo Vespucio, s/n. 41092 Sevilla, España jcsuarez@us.es

\section{Resumen}

La profesión periodística se enfrenta a un nuevo entorno comunicativo digital en el que los tradicionales flujos informativos, emanados desde los medios de comunicación hacia los ciudadanos de forma unidireccional, cambian debido a los nuevos canales de participación e influencia que las audiencias, activas y dinámicas en las redes, utilizan para incidir en la configuración de la opinión pública. Se describen y analizan algunas de las prácticas informativas ciudadanas y los dilemas éticos que plantean respecto al periodismo y el derecho a la información.

\section{Palabras clave}

Internet, Periodismo, Participación ciudadana, Ética, Opinión pública, Deontología, Redes sociales.

\section{Title: Ethics of citizen participation in the digital journalistic discourse}

\section{Abstract}

The journalism profession is facing a new digital communication environment in which traditional information flows, emanating from the media to the general public unidirectionally, are reversed under the new channels of participation and influence that audiences, which are active and dynamic on the network, use to take part in shaping public opinion. In this paper we describe and analyze some of the citizens' information practices and the ethical dilemmas posed about journalism and the right to information.

\section{Keywords}

Internet, Journalism, Citizen participation, Ethics, Public opinion, Deontology, Social networks.

Cruz-Álvarez, Jesús; Suárez-Villegas, Juan-Carlos. "Ética de la participación ciudadana en los discursos periodísticos digitales". El profesional de la información, 2012, julio-agosto, v. 21, n. 4, pp. 375-380.

http://dx.doi.org/10.3145/epi.2012.jul.07

\section{Un nuevo entorno comunicativo en la Red}

El implacable desarrollo de las nuevas tecnologías de la información ha contribuido a configurar un entorno comunicativo digital complejo, altamente dinámico y retroalimen-

Artículo recibido el 19-04-12

Aceptación definitiva: 17-05-12 tado por un denso entramado de nodos de interconexión que reactualizan instantáneamente los contenidos que jaIonan la Red. En la actualidad, cualquier usuario con acceso a la misma y unas nociones básicas de su utilización es susceptible de producir información que es consumida a menor 
o mayor escala en alguna de las múltiples extensiones de un sistema comunicativo global.

Se trata de la asunción de un nuevo tipo de ciudadanía participante que focaliza su actividad en las redes digitales a partir de una estructura horizontal de producción y difusión de contenidos por la que se rompe con la hegemonía tradicional de los grandes medios de comunicación. El mensaje unidireccional propio de la prensa escrita, la televisión o la radio se diluye ahora en una amalgama de mensajes dispersos mediados por las nuevas herramientas sociales, de manera que es el propio usuario el que adquiere notoriedad pública frente a la mayor visibilidad consustancial de los medios, gracias al eficaz manejo de redes sociales o programas tecnológicos virales.

El periodista digital contempla así cómo su pertenencia a una estructura empresarial determinada no es condición exclusiva para mantener el monopolio de la información en un entorno en el que su mensaje se difumina entre una cantidad indefinida de contenidos producidos por los propios usuarios. Éstos han contribuido a revertir el clásico patrón del flujo informativo de arriba hacia abajo en uno nuevo que discurre de abajo hacia arriba (aunque la figura más fiel sería la del fractal), de manera que se erigen incluso como fuentes y amplificadores irrenunciables del trabajo cotidiano de los periodistas.

Las vías de participación ciudadana habilitadas por los medios en sus versiones digitales (que a su vez superaban las obsoletas formas de contacto como las cartas al director en los diarios) han resultado ser insuficientes para albergar el imparable desarrollo del usuario activo digital. Ya no se trata de agregar un espacio accesorio para que los lectores expresen sus opiniones acerca de un determinado artículo o reportaje, sino de incluir a éste en el proceso informativo ya sea a través de material original (fotografías, vídeos, declaraciones, etc.) o de la difusión de los contenidos mediante redes sociales. El perfil del usuario digital no puede asimilarse al del teleespectador tradicional, marcado por cierta pasividad y resignación, sino que se caracteriza por un dinamismo que lo insta a participar, compartir e incluso crear contenidos. Se trata, al fin, de un fenómeno más en la caótica composición de la nueva esfera de la comunicación social, definido por Manuel Castells (2009) como la "autocomunicación de masas" o, lo que es lo mismo, la individualización del consumo y producción de comunicación.

Podríamos incluso aseverar que la noticia queda reducida a su expresión más fugaz, destinada a ser olvidada casi a la par que es conocida. Tiene una vocación meramente publicitaria del acontecimiento que busca más una finalidad de consumo sociológico del hecho que una actitud reflexiva sobre el mismo. Todos lo conocen y como tal lo comentan. De este modo la reacción de los ciudadanos se convierte en nuevo acontecimiento que puede superar en su atención al propio hecho que lo originó. Es un modo de creación de noticias a través de las noticias, la manera de aprovechar la sinergia informativa para fomentar determinados discursos. En cierto modo, este modelo de participación de la ciudadanía como feedback de los hechos noticiosos puede ser utilizado para darle a la noticia un valor a partir de su efecto "sociológico".

\section{Identidad difusa del periodismo}

¿Cómo entender este proceso de periodismo desde el margen? ¿Qué riesgo puede tener para el derecho a la información del público la participación de los ciudadanos en el proceso informativo? ¿Es real este proceso de participación de los ciudadanos o más bien es una argucia utilizada por el medio para elegir aquellas intervenciones que puedan representar un debate popular que sólo actúa con feedback de las intenciones comunicativas del medio? ¿Es conveniente este modo de entender la profesión periodística?

\section{La reacción de los ciudadanos se con- vierte en nuevo acontecimiento que puede superar en su atención al hecho que lo originó}

El periodista debe convivir junto a millones de usuarios que actúan de acuerdo con valores divergentes a los que impele la profesión, propiciando tensiones éticas que se vinculan con el modo de concebir la información. Los principios del contraste y verificación, la precisión, la imparcialidad o la rigurosidad de la cultura periodística se enfrentan a la inmediatez, la transparencia, la utilización de fuentes no oficiales o la corrección a posteriori del periodismo online no profesional. La identidad del periodismo se distorsiona en virtud a la democratización del entorno comunicativo y surgen así las preguntas indisolubles de qué puede considerarse o no periodismo o cuáles son las características definitorias del mismo.

No obstante, este fenómeno no puede concebirse de forma aislada o espontánea. El incremento exponencial de contenidos informativos de la mano de esa suerte de ciudadanía activa digital puede entenderse como una reacción frente a la notoria pérdida de credibilidad del periodismo tradicional, percibido por la sociedad como una disciplina instrumentalizada por poderes políticos y económicos en pos de una serie de intereses ajenos a la conformación de una opinión pública. Parece que tienda al activismo político en su sentido primigenio, aquel en el que el pluralismo y el debate sirvan para dirimir los problemas inherentes a cualquier tipo de organización humana. En este sentido, el cometido de los medios de comunicación es el de ejercer de correa de transmisión entre la ciudadanía y los poderes públicos basándose en el pilar institucional democrático de la libertad de expresión. El problema surge cuando quedan cooptados por la esfera política e imponen sus prácticas de dominación en el espacio social de la comunicación revirtiendo negativamente en el desarrollo del derecho de la ciudadanía a ser informada verazmente.

Tal y como apunta Núñez-Encabo (2011), "sigue siendo inmutable la exigencia del derecho constitucional y fundamental de los ciudadanos a recibir informaciones plurales, veraces y opiniones libres y éticas en todos los temas de interés general, respetando los derechos fundamentales de la persona -en el marco del art. 20, título I, de nuestra Constitución-, y para ello la garantía es que existan profesionales de la información con dos requisitos imprescindibles: (a) 
Formación adecuada para la elaboración, interpretación y transmisión de los contenidos informativos a los ciudadanos a través de los medios de comunicación y (b) compromiso público de asumir su responsabilidad deontológica".

La tarea de la sociedad es reclamar de los medios de comunicación su función de instrumento social, promotores del diálogo, la tolerancia y el pluralismo. Sin embargo, ante el abandono sistemático de estos medios de sus deberes, la ciudadanía ha optado por socavar la preponderancia de los discursos mediáticos de los grandes grupos en la opinión pública infiltrándose en los ámbitos de producción y difusión de contenidos que las nuevas tecnologías digitales brindan a sus usuarios a coste cero y con herramientas cada vez más simplificadas. Este es el origen de lo que se ha venido a llamar "periodismo ciudadano", aunque en cierto modo las prácticas desarrolladas en la Red van más allá de los límites de la profesión periodística y se vinculan en mayor medida con una comunicación transversal y descentralizada que podríamos catalogar como una opinión pública 3.0'.

La participación de la ciudadanía puede entenderse como una reacción frente a la notoria pérdida de credibilidad del periodismo tradicional, percibido como una disciplina instrumentalizada por poderes políticos y económicos

Pau Llop (2006) asevera que "La revolución no es sólo contra el consumo de información habitual de la última mitad del siglo $X X$, sino contra los medios como instrumentos de mediación entre los ciudadanos y el poder, entre las noticias y su comprensión. La comunicación de masas creada y fortalecida por los diarios, la radio y la televisión durante más de un siglo se resquebraja, y los modelos de negocio basados en el público amplio y la institucionalización de mensajes homogeneizados se diluye en un nuevo sistema de saturación informativa, comoditización de la información, donde la distribución descentralizada y de redes sustituye a la vieja estructura de la comunicación de masas: difusión de uno a muchos".

Dan Gillmor, máximo referente teórico del periodismo ciudadano tras la publicación de su libro We the media en 2004, va más allá y sostiene que el ciudadano puede incluso mejorar el trabajo de los periodistas, no sólo como productor sino como vigilante de los medios. Estos perderían su tradicional función de gatekeeper, es decir su capacidad para filtrar en régimen de monopolio los hechos de la realidad según criterios informativos, políticos o económicos, y cederían parte de esta responsabilidad a las masas de usuarios, que según Axel Bruns (2005) adoptarían el papel activo de gatewatching o "cazadores de tendencias" en la Red a partir del cual alertar a los periodistas de los acontecimientos noticiosos.

Para entender en profundidad el nuevo fenómeno de la comunicación digital, conviene diferenciar dos modalidades de participación ciudadana:

1) aquella que es albergada en los medios de comunicación como una suerte de concesión controlada (en su publicación) a las audiencias en un intento de realizar un periodismo más abierto que se suma a las nuevas tendencias (aunque su verdadero impacto sea muy limitado). De acuerdo con Xosé López (2007), este tipo supone a su vez un reto y una oportunidad que afrontar con la idea de que "las redacciones de los cibermedios tienen que establecer sistemas de organización renovados para asegurar una correcta gestión de esas vías de participación a fin de que, bajo la coordinación de los profesionales de la información, redunden siempre en una información de mayor calidad";

2) los sitios web desarrollados bajo la etiqueta de periodismo ciudadano, como Bottup en España, o el referente internacional Oh My News, el mayor centro de información digital de Corea del Sur con más de 50.000 contribuyentes y 40 editores, los cuales han sembrado un interesante debate en torno a su identidad periodística al no estar sujetos a los criterios profesionales tales como la veracidad de la información, el contraste de fuentes o la selección temática.

\section{Formas de incidencia de la ciudadanía}

El periodismo ciudadano, definido originalmente por Bowman y Willis como "los actos de los ciudadanos, jugando un rol activo en la adquisición, reporte, análisis y difusión de noticias e información" (2003, p. 99), también ha sido concebido como una oportunidad irrenunciable para la consecución de una democracia deliberativa real que vaya más allá de la esfera pública liberal por la que los ciudadanos asisten pasivamente como observadores a la representación de la realidad ofrecida por los medios de comunicación. Para ello

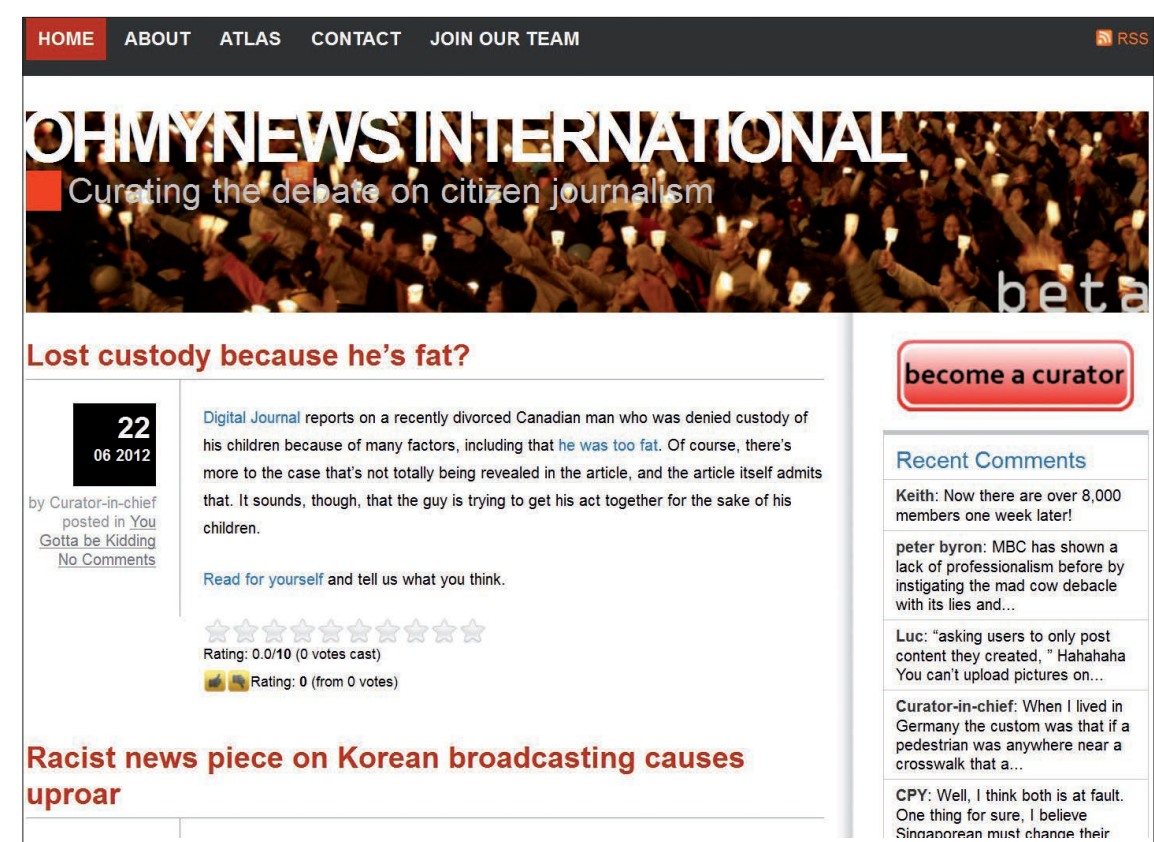

http://international.ohmynews.com 


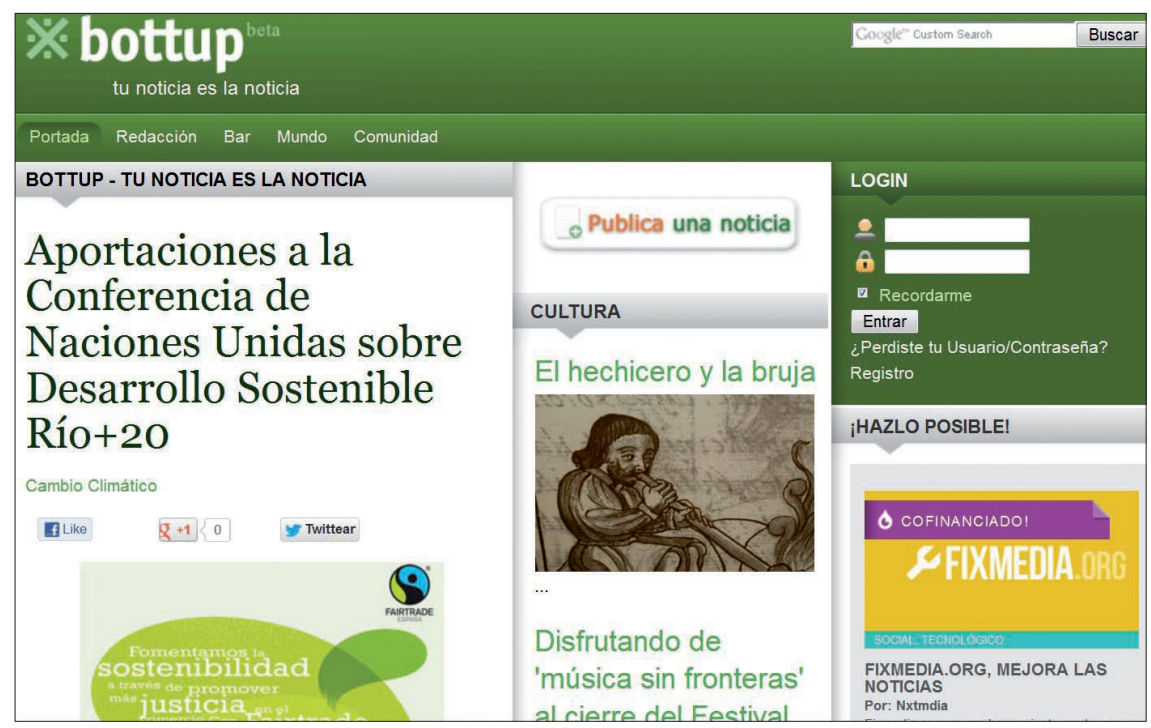

http://bottup.com

se antoja fundamental la constitución de una esfera pública deliberativa basada en la participación, la argumentación y el bien común (Lamuedra, 2012).

Y esa esfera pública halla su entorno más propicio en la Red a partir "del logro de ese papel activo que siempre se ha demandado del receptor-público-audiencia -usuario en el proceso informativo-comunicativo" (Real et al., 2007)-. Nos situamos en una coyuntura en la que la web participativa (definida por la OCDE (2006) como "aquella que permite a los usuarios contribuir a desarrollar, calificar, colaborar y distribuir contenido de internet y personalizar las aplicaciones") posibilita la inclusión de la ciudadanía en el proceso de constitución de la opinión pública, haciendo valer su derecho fundamental avalado por la Constitución española no sólo a recibir, tal y como apuntábamos anteriormente, sino también a difundir información veraz.

Así pues, tanto el periodismo ciudadano como otras formas de comunicación espontáneas surgidas con las nuevas tecnologías digitales, se encuentran legitimadas legalmente para el ejercicio de transmitir información de forma independiente. Ahora bien, los dilemas éticos que plantea la erosión de la profesión periodística frente al empuje de los nuevos actores de la comunicación en las redes es un debate que trasciende las fronteras de la opinión pública y supone una peligrosa tendencia que podría augurar el fin mismo del periodismo.

\section{El caso de Fixmedia}

Tal y como nos hemos referido a lo largo de este artículo, las posibilidades de las nuevas tecnologías digitales han revolucionado las prácticas informativas tradicionales al romper la estructura vertical hegemónica de los medios de comunicación en el proceso de recolección, producción y difusión de las noticias. Ahora el ciudadano devenide $8.205 €)$.

http://fixmedia.org do en usuario detenta la capacidad de crear sus propios contenidos e incluso de repercutir en la configuración de la agenda mediática a través de las redes sociales o de otras herramientas de influencia viral. No obstante, la preponderancia de los medios de comunicación continúa siendo notoria también en internet, y sus discursos acabados, cerrados y con fecha de caducidad a pesar de las vías de participación habilitadas para comentarios de los lectores. Es decir, el periodista confecciona la noticia y ésta queda inalterada (a menos que contenga un error flagrante o precise de una actualización oportuna) en la Red, al igual que lo hacía en un periódico impreso; las audiencias no tienen acceso a él.

Esta es una realidad que, sin embargo, parece que está destinada a cambiar con la asunción de una nueva herramienta social denominada Fixmedia que pretende alterar la cadena de producción de la noticia abriendo al público la posibilidad de corregir o "hackear" su contenido. Desarrollada por Nxtmedia, una empresa social responsable, entre otros proyectos, de Bottup o Periodismo Humano, y dirigida por el emprendedor digital Pau Llop, Fixmedia se encuentra en proceso de recogida de fondos en el sitio web de financiación colectiva (crowdfunding) Goteo.org. (el 2 de junio de 2012 informó haber alcanzado su objetivo

Su funcionamiento se ciñe a dos elementos; por un lado un marcador alojado en el navegador web del usuario al que se accede cuando se desee realizar una corrección o ampliación al contenido informativo que se está leyendo; por otro, la web de Fixmedia.org, concebida como el lugar de en-

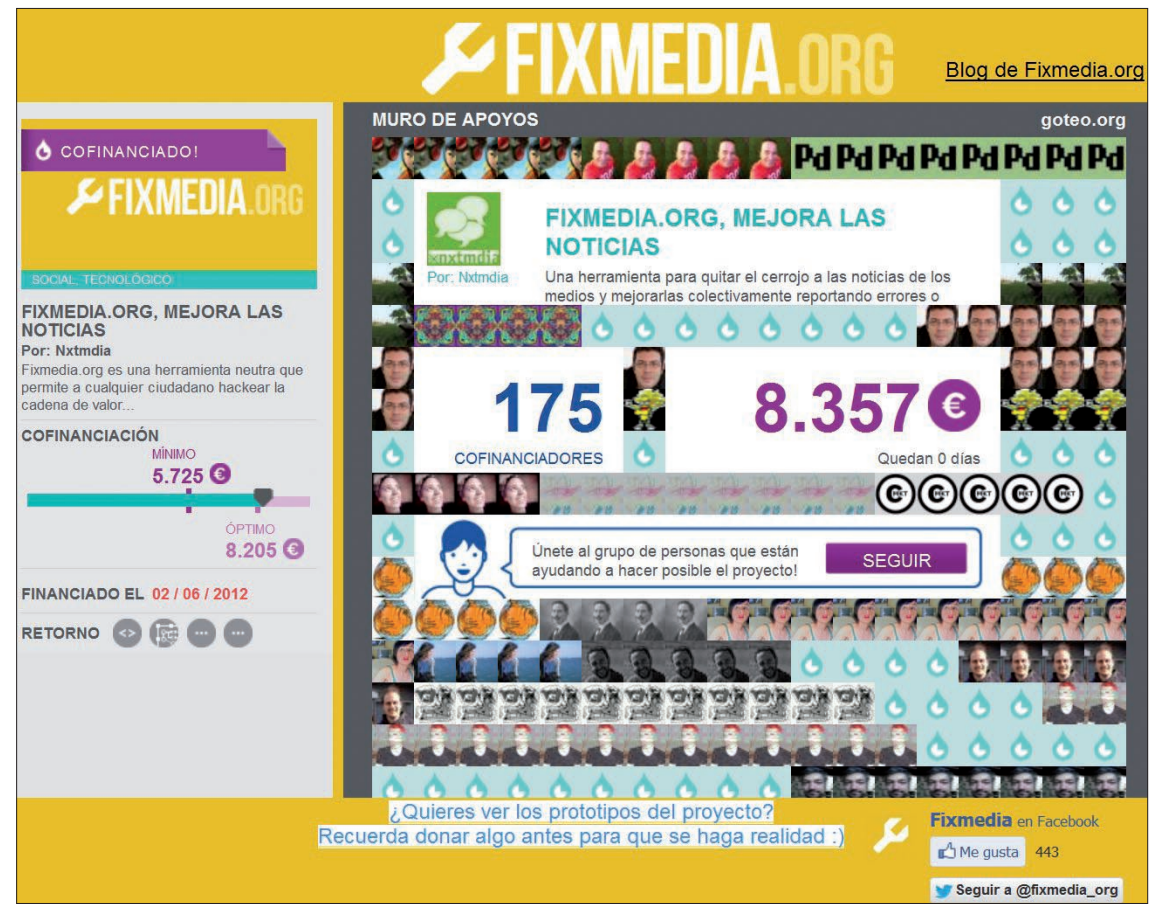


cuentro de todos los reportes realizados por la comunidad de editores que serán sometidos a debate y evaluación.

El objetivo es que todos los usuarios tengan la posibilidad de señalar errores tales como una declaración sin citar, una información no contrastada, un titular tendencioso o una redacción con errores gramaticales, así como apuntar posibles ampliaciones como citas, gráficos o datos no contemplados, de manera que el producto final del periodista se vea mejorado.

"Vivimos tiempos malos para el periodismo, y los medios tradicionales abrazan la interpretación olvidando abordar la actualidad desde un enfoque netamente factual, máxime en momentos convulsos donde estos medios pugnan por construir una imagen de la realidad acorde a sus intereses, sin tener en cuenta que la realidad ya no se puede construir unilateralmente nunca más. El objetivo de Fixmedia.org es ser un primer paso decisivo en la mejora del periodismo a través de la inteligencia colectiva". De este modo se presenta la herramienta digital en su web al tiempo que lanza la pregunta: “¿Cómo puede ser que miles de lectores no puedan mejorar una noticia creada por una sola persona?".

La trascendencia de este nuevo tipo de posibilidades tecnológicas digitales abre un interesante debate en torno a los cada vez más difusos límites entre el periodismo profesional y la amalgama de prácticas pseudo-periodísticas que proliferan en la Red. La identidad del periodista queda, así, desdibujada por la concurrencia de nuevos actores en la configuración de los flujos mediáticos que, a su vez, determinan su labor a posteriori. Los canales de participación ciudadana en los discursos informativos se filtran hasta el proceso mismo de producción con el objeto de construir una opinión pública entre todos en "un contexto tecnológico que nos permite tratar las noticias como procesos" abiertos en lugar de como productos" cerrados".

\section{El contexto tecnológico permite tratar las noticias como procesos abiertos en lugar de como productos cerrados}

\section{Dilemas éticos de la participación ciudadana en los discursos mediáticos}

La democracia se basa en la idea de la participación de la ciudadanía, una ciudadanía ilustrada que busca en la información criterios para formar su opinión y lograr consensos mayoritarios que legitimen la acción política. No obstante, este concepto de participación, que es horizontal y abierto para todos los miembros de una comunidad, entra en conflicto con otro elemento capital para un ejercicio equilibrado del derecho de información: la responsabilidad. Los medios de comunicación son atribuidos legalmente con la función de administrar la libertad de expresión y, consecuentemente, rinden cuentas ante ella cuando sus prácticas no se adecuan a los códigos deontológicos que rigen la profesión. La responsabilidad informativa es, por tanto, vertical y atañe tanto a los propios periodistas como a las empresas en las que se insertan.
Y es que el derecho a la información, si bien su titularidad corresponde a todos los ciudadanos, recae con mayor peso en el ejercicio que del mismo se realiza desde los medios de comunicación no sólo por su mayor repercusión, sino también por ser depositarios de una confianza en un bien que debe administrar adecuadamente. "No se trata de un derecho distinto, pero sí de un derecho de ejercicio con una finalidad de asegurar el derecho de la ciudadanía. La labor profesional del comunicador se convierte en un deber, al serle exigible una responsabilidad social y una diligencia en su quehacer informativo cualificado" (Suárez, 2011). Esta condición inherente al periodismo, si bien es eludida de forma recurrente en el seno de las grandes empresas de comunicación por motivos de diversa índole, se erige como requisito previo a cualquier tipo de práctica informativa, la cual exige, por ende, una profesionalidad tan sólo hallada en el periodismo.

\section{Es fundamental un repliegue del perio- dismo hacia conductas respetuosas con los códigos deontológicos de la profe- sión}

Es decir, que la principal distinción entre el periodismo profesional ejercido en los medios de comunicación tradicionales (ahora también digitales) y las prácticas informativas llevadas a cabo por la gran masa de usuarios de internet, englobadas en el denominado periodismo ciudadano, se basa en los principios éticos compartidos por la profesión periodística como pilar institucional de la democracia en cuanto administradores de la libertad de expresión y valedores primordiales del derecho a la información de la ciudadanía. Por ello se antoja fundamental un repliegue del periodismo hacia conductas respetuosas con los códigos deontológicos de la profesión con el objetivo de definirse autónomamente en un entorno comunicativo complejo donde los flujos informativos discurren en todas direcciones. "Se trataría, pues, de llevar a cabo una autorregulación voluntaria a partir de la libre iniciativa de los periodistas que se situaría entre el derecho y la práctica periodística, guiada por criterios y principios éticos" (Micó et al., 2008).

En la misma línea, Núñez-Encabo (2011) prosigue: “Conviene precisar el concepto claro de deontología del periodismo para lo cual hay que partir de que es una ética pública y no privada, lo que lleva a su responsabilidad pública ante los ciudadanos y no sólo ante la conciencia individual del periodista. Por tanto, sólo será eficaz si los compromisos éticos se plasman en normas recogidas y publicadas en códigos deontológicos con el compromiso voluntario -la Ética nunca debe imponerse, a diferencia del Derecho- de someterse a las resoluciones de comisiones de quejas y deontología independientes y autónomas en su funcionamiento, de los propios medios y de los periodistas -como es el modelo de la $F A P E^{1}$ - con el compromiso además de aceptar la publicación de sus resoluciones desde los medios de comunicación, para conocimiento de los ciudadanos que valorarán así su credibilidad, con efectos en la utilización o alejamiento de los mismos". 
Podemos concluir a este respecto que sin el cumplimiento escrupuloso de los principios deontológicos, el periodismo como profesión carecería de sentido ante el empuje de otras prácticas no institucionalizadas a las que legitimaría por el descrédito cosechado ante la ciudadanía, que se ve obligada a buscar más allá de los discursos mediáticos la información de interés público que en ellos no encuentra.

Podríamos considerar a los ciudadanos acarreadores de información mientras que los periodistas deberían ser constructores de opinión

\section{Conclusión}

Los periodistas parecen haber perdido el peso de su función social debido a que muchos otros ciudadanos también realizan esta tarea de intermediación entre los acontecimientos y el público, ya sea a través de los propios medios o por diversos soportes electrónicos como redes sociales o sus propios blogs. La complejidad se halla en descifrar cuál sería entonces la diferencia entre este tipo de actividad de difusión abierta de la información y aquella otra que se encuentra atribuida de una responsabilidad pública, específica de quienes asumen una función como constructores de la opinión pública, los periodistas. De este modo, los ciudadanos podríamos considerarlos "acarreadores" de información mientras que los periodistas deberían ser "constructores de opinión". Lo importante no es reproducir en los espacios digitales el ruido ambiente que se cuela por la ventana mediática, sino que el periodista ofrezca una información con criterios, capaz de teorizar (hacer ver) la realidad con perspectiva crítica y analizar los hechos desde un diseño de valores sociales.

Es decir, el nuevo entorno comunicativo forjado al calor del implacable desarrollo de internet y las tecnologías digitales que gravitan en torno a él, ofrece innumerables oportunidades para configurar un modelo informativo más horizontal y descentralizado a partir de la participación activa de la ciudadanía en virtud a sus propios derechos constitucionales de libertad de expresión y derecho a la información. No obstante, esta circunstancia no niega el rol trascendental de la profesión periodística en la configuración de la opinión pública, sino que debe reforzarlo en cuanto es más acuciante la responsabilidad exigible a los periodistas de acuerdo con las normas deontológicas que inspiran su ejercicio.

\section{Nota}

1. FAPE (Federación de Asociaciones de Periodistas de España)

http://www.fape.es

\section{Bibliografía}

Bowman, Shayne; Willis, Chris. We media: how audiences are shaping the future of news and information. The Media Center at the American Press Institute, 2003.

http://www.hypergene.net/wemedia/download/we_me dia.pdf

Bruns, Axel. Gatewatching, collaborative online news production. New York: Peter Lang Publishing, 2005. ISBN: 978 0820474328

Castells, Manuel. Comunicación y poder. Alianza Editorial, Madrid, 2009. ISBN: 9788420684994

Guillmor, Dan. We the media. O'Reilly, 2004. ISBN: 0596 007337

http://oreilly.com/openbook/wemedia/book/index.html

Lamuedra, María. "Percepción de la realidad mediática y deontología periodística: hacia un periodismo participativo acorde con una democracia deliberativa". Observatorio (OBS*) journal, 2012, v. 6, n. 1, pp. 183-209.

http://obs.obercom.pt/index.php/obs/article/view/546/ 483

Real-Rodríguez, Elena; Agundiez-Calvo, Pinar; PríncipeHermoso, Sergio. "Periodismo ciudadano versus periodismo profesional”. Estudios sobre el mensaje periodístico, 2007, n. 13, pp. 189-212.

Llop, Pau. "Hacia la ciberdemocracia a través del periodismo ciudadano: la formación, el paso perdido por los medios tradicionales y la oportunidad de los nuevos medios". Razón y palabra, 2006, dic.-enero, v. 11, n. 54.

http://www.razonypalabra.org.mx/anteriores/n54/p/lop. html

López, Xosé. "Gestión de las vías de participación en el ciberperiodismo". Estudios sobre el mensaje periodístico, 2007, n. 13, pp. 111-121.

Micó, Josep-Lluís; Canavilhas, João; Masip, Pere; Ruiz, Carles. "La ética en el ejercicio del periodismo: credibilidad y autorregulación en la era del periodismo en internet". Estudos em comunicação, 2008, n. 4, pp. 15-39.

http://www.ec.ubi.pt/ec/04/pdf/02-Jose-Lluis-Mico-La-eti ca-en-el-ejercicio-del-periodismo.pdf

Núñez-Encabo, Manuel. "La ética en el periodismo multimedia actual". Perspectivas de la comunicación, 2011, v. 4, n. 1, pp. 166-171.

http://www.perspectivasdelacomunicacion.cl/revista_1_ 2011/03_documento.pdf

OCDE. Participative web and user-created content: web 2.0, wikis and social networking. Directorate for Science, Technology and Industry. OCDE: Paris, 2006.

Suárez-Villegas, Juan-Carlos. La libertad de expresión en España y Latinoamérica. Dickynson, 2011. ISBN: 978 8499822556 